\title{
ONDE FOI PARAR A INTERNET NOS DISCURSOS DO BRASIL NA ASSEMBLEIA GERAL DA ONU EM 2015 E 2016?¹
}

\section{Where was the Internet in the remarks of the Brazilian Presidents at the UN General Assembly in 2015 and 2016?}

\author{
Diego Rafael Canabarro ${ }^{2}$
}

Em 2013, quase que imediatamente após terem sido divulgadas as primeiras revelações de Edward Snowden (sobre o grande esquema de espionagem e vigilância em funcionamento sob os auspícios da Agência de Segurança Nacional dos Estados Unidos) a então presidente do Brasil proferiu um discurso contundente na abertura da 68a Assembleia Geral da ONU (BRASIL, 2013).

As repercussões desse pronunciamento (bem como de uma série de desenvolvimentos paralelos que ganharam força com o caso Snowden) levaram o governo estadunidense a anunciar a sua intenção de efetivamente deixar o papel de supervisor-garante do correto desempenho das funções IANA (EUA, 2014) as funções de coordenação central (das alocações de endereços IPs, do sistema de nomes de domínios e das designações atribuídas aos protocolos estruturantes da rede), que garantem que a Internet funcione como um espaço global único e não fragmentado3. Por anos, elas foram executadas por acadêmicos estadunidenses envolvidos com o projeto da Internet. Nos últimos dezoito anos, elas foram assimiladas por uma corporação privada sem fins lucrativos dos EUA mediante a supervisão do Departamento de Comércio do país. É dessa posição privilegiada que o governo Obama resolveu abrir mão em 2014.

A execução das funções IANA perfaz uma parte bem delimitada (de caráter extremamente técnico) da governança da Internet vista por uma perspectiva mais ampla, nos moldes delineados pela Cúpula

\footnotetext{
1Este texto é uma versão revisada, adaptada e ampliada de uma postagem no Observatório da Internet no Brasil. O autor agradece os integrantes da Rede de Articulistas do Observatório [nomes suprimidos para garantir o anonimato da revisão editorial] que criticaram e comentaram a primeira versão do texto.

${ }^{2}$ Doutor em Ciência Política; mestre em Relações Internacionais e Bacharel em Direito pela Universidade Federal do Rio Grande do Sul (UFRGS). É advogado inscrito na OAB/RS sob o número 68.870. Pesquisa na área de Política Internacional, com ênfase em: 1) Tecnologia, Estado e Segurança Internacional; 2) governança digital; e 3) governança da Internet. De 2009 a abril de 2014, atuou como pós-graduando responsável pelo GT Governança Digital e assistente de ensino e pesquisa do Prof. Marco Cepik no Centro de Estudos Internacionais sobre Governo (CEGOV/UFRGS). Realizou estágio doutoral no National Center for Digital Government da Universidade de Massachusetts, Amherst, sob a supervisão da Prof. Jane Fountain durante o ano acadêmico de 2012/2013. Atualmente, trabalha na Diretoria de Assessoria ao Comitê Gestor da Internet no Brasil (CGI.br) do Núcleo de Informação e Coordenação do Ponto br (NIC.br). Email: diegocanabarro@gmail.com

3 Para um detalhamento do funcionamento das atividades relacionadas à IANA, ver o documento ilustrativo disponível em: https://www.icann.org/en/system/files/files/functions-basics-07apr14-en.pdf. Acesso em: 16/06/2017.
} 
Mundial para a Sociedade da Informação, entre 2003 e 20054, e cuja pauta contemporânea ganhou em complexidade e abrangência. Diante dessa complexidade (e, até mesmo, da dificuldade de se traçar os limites entre o todo e a parte), o caso Snowden aumentou a confusão geralmente existente entre a extensão (a) da preponderância de atores governamentais e não governamentais dos Estados Unidos na economia política da era digital (Gonzales, 2016) como um todo e (b) do papel do Departamento de Comércio na tarefa restrita de auditar o correto funcionamento das funções IANA, aferindo sua conformação às políticas adotadas pelos fóruns técnicos especializados para nomes, números e protocolos da Internet (CANABARRO; BORNE, 2015). Em 2014, a questão voltou a aparecer no discurso do Brasil na abertura da Assembleia Geral da ONU (BRASIL, 2014), como uma espécie de balanço parcial do movimento posto em marcha no ano anterior.

Em 2015, porém, nenhuma palavra foi proferida sobre o assunto por Dilma (BRASIL, 2015). Há articulistas mais vetustos e doutos no assunto, que nos ajudam a entender as razões preponderantes para a lacuna. De maneira geral, a opção por um “discurso protocolar” e com uma forte tendência à “introversão” reflexo da progressiva perda de importância da política externa no governo Dilma (CASARÕES, 2015) deveu-se sobretudo ao fato de ter sido formulado em meio ao turbulento agravamento da crise política que culminou, em 2016, com seu afastamento sumário do Planalto. O discurso de 2015, nesse sentido, dirige-se à (parca) audiência interna; e serve como forma de procurar legitimidade internacional frente ao movimento que postulava seu impedimento no âmbito doméstico. Ao mesmo tempo em que trouxe ponderações sobre as tradicionais linhas mestre que são permanentes na inserção internacional no Brasil (e.g: reforma do Conselho de Segurança, a integração regional com os países do Sul e a segurança internacional no entorno estratégico), o discurso limitou-se à agenda conjuntural de 2015 - que tinha a agenda ambiental (diante da Conferência de Paris sobre Mudanças Climáticas no fim do ano) e a questão dos refugiados (sobretudo por conta do conflito sírio) como aspectos mais prementes.

A lacuna pode ser explicada, também, por razões mais diretamente relacionadas com a evolução dos temas relativos à governança da Internet (e aqui ousamos dar alguns palpites). A trilha NETmundial tinha recém sido inaugurada. A transformação pretendida no "roteiro de São Paulo" é algo que deverá surtir efeitos mais perceptíveis no médio e no longo prazo. As reformas mais tangíveis resultantes do ímpeto de 2013, consubstanciadas na abertura de um processo de desenho de uma proposta para a transição da supervisão das funções IANA, estavam em pleno processo de construção e discussão no âmbito, e o seu resultado estava ainda indefinido. Nesse sentido, talvez teria sido desejável que houvesse uma reiteração explícita da importância de não se retroceder nesse campo. Mas só quem pode explicar as razões para que isso não fosse ressaltado perante a ONU são as pessoas envolvidas diretamente com a assessoria internacional da Presidência da República.

4 A UIT mantém um portal permanente contendo a documentação produzida no contexto da Cúpula: https://www.itu.int/net/wsis/index.html. Acesso em: 16/06/2017. 
Uma outra crítica que poderia ser apontada à manifestação de 2015 diz respeito à ausência de manifestação de apoio, pelo Brasil, à renovação do mandato do Fórum de Governança da Internet5. Pode ser que isso se justifique pelo fato de que essa renovação corria em um processo paralelo, com espaço pertinente para o país firmar sua posição. Ainda assim, poucos meses depois do discurso, o Brasil sediou a 10a edição do Fórum, em João Pessoa, na Paraíba, tendo sido o único país do mundo a contar com o privilégio de sediá-lo por duas ocasiões (a anterior foi em 2007). Apesar de o tema ser granular, a diplomacia brasileira perdeu uma oportunidade relevante de intensificar a promoção do modelo brasileiro de governança da Internet (capitaneado pelo CGI.br - o Comitê Gestor da Internet no Brasil6) como inspiração para os demais países (que tem servido como elemento de soft power para a diplomacia brasileira no setor correspondente); e - com isso - pressionar, ainda mais, pelo avanço da democratização da governança global da Internet, da qual o IGF é o principal símbolo há dez anos.

Em 2016, o atual presidente brasileiro repetiu a lacuna observável no discurso anterior (BRASIL, 2016). Parcialmente, pelas mesmas razões que explicam a lacuna em 2015: criar uma narrativa de normalidade institucional que faça sentido do ponto de vista dos cidadãos no contexto pós-impeachment e que sirva à busca de legitimidade internacional, mantendo um perfil protocolar e sem grandes direcionamentos e proposições (CASARÕES, 2016). Mas se a conjuntura de 2015 desabona a lacuna de então, o mesmo não valeu para 2016, pelo simples fato de ter sido o ano crucial para a conclusão do processo de desvinculação da raiz da Internet da supervisão do Departamento de Comércio, encerrando com isso - o "longo 2014 da governança da Internet" (CANABARRO, 2015), inaugurado precocemente, em grande medida, pela ação do Brasil, ainda em 2013.

O contrato entre o Departamento de Comércio dos Estados Unidos e a ICANN7 (entidade responsável por executar as funções IANA), sucessivamente renovado desde 2000, expirou em 30 de setembro de 2016. O governo Obama trabalhou no sentido de não renovar o acordo e repassar (mediante a imposição de uma série de condicionalidades (STRICKLING, 2016)), finalmente, tal responsabilidade à própria comunidade da ICANN, conforme o anunciado em 2014. Diz-se, na literatura especializada e no discurso político, que o governo do país (tanto sob a égide de Democratas, quanto de Republicanos), desde a criação da ICANN em 1998, teve a intenção de transferir suas prerrogativas à “comunidade multissetorial da Internet”. Isso demorou quase 20 anos, o que levanta suspeitas sobre a alegação - mas não há espaço, neste texto, para problematizar esse ponto.. A precipitação da transição, em 2014, geralmente é apontada como decorrência da pressão internacional que cresceu após Snowden. Pode ser, porém, que tenha resultado da intenção da diplomacia estadunidense de delimitar e restringir os contornos da agenda política que se criou para contra-arrestar a centralidade do país na economia política da era digital após o escândalo (tanto é que o anúncio foi feito um mês antes do NETmundial em São Paulo). Com o tempo saberemos com mais exatidão e, em outras oportunidades, abordarei um pouco mais a respeito.

5 Maiores informações sobre o “Internet Governance Forum”, organizado pela ONU desde o encerramento da Cúpula Mundial sobre a Sociedade da Informação, estão disponíveis em: https://www.intgovforum.org/multilingual/. Acesso em: 16/06/2017.

6 Maiores informações sobre o CGI.br estão disponíveis em: https://cgi.br. Acesso em: 16/06/2017.

7 Maiores informações sobre a ICANN estão disponíveis em: https://www.icann.org. Acesso em: 16/06/2017. 
A ICANN - incorporada sob as leis da Califórnia (algo contestado historicamente pela diplomacia brasileira (LUCERO, 2011)) - não funciona apenas como a entidade que executa as funções IANA. Ela serve, também, como o fórum central para adoção de políticas (que tem natureza transnacional) para o sistema de nomes de domínio na Internet. Envolvem-se com a ICANN, na condição de arena política, mais de 170 governos, organizações intergovernamentais e não governamentais, milhares de empresas de todo o planeta (envolvidas diretamente com a economia do DNS ou, apenas indiretamente, na qualidade de provedoras de serviços e usuárias da Internet), usuários individuais, e setores da comunidade científica e tecnológica que têm a Internet como cerne de suas atividades. Se a transição for confirmada, essa organização internacional não governamental sem fins lucrativos ficará responsável por assegurar que as funções IANA sejam desempenhadas adequadamente sem a supervisão dos funcionários do Departamento de Comércio. Para isso, foi projetado um novo arcabouço institucional, desenvolvido entre 2014 e 2016, para acomodar a nova realidade8.

A palavra final sobre a transição foi dada (ainda que por consentimento silencioso), no fim de setembro de 2016, pelo Congresso do país. Isso ocorreu poucas semanas antes das eleições presidenciais que definiram Donald Trump como o sucessor de Obama. Nesse contexto, cresceu em visibilidade a oposição do Senador Ted Cruz à transição. Para Cruz (do Partido Republicano) - ainda que com pouca atenção à veracidade dos fatos e com muito alarde retórico -, o governo Obama pretendia abandonar seu papel iluminado, de garante da "liberdade de expressão" na Internet, estando disposto a abrir espaço para que países como “China, Rússia, Irã e outros inimigos da liberdade” tenham mais protagonismo na governança dos recursos críticos à governança da rede9. Nesses termos, a continuidade do unilateralismo dos Estados Unidos na supervisão da IANA seria menos pior que a alternativa adotada (uma solução, pelo menos conceitualmente, mais plural e participativa).

Cruz - que chegou a ser endossado publicamente por Donald Trump (MCCARTHY, 2016) geralmente apresenta a ICANN como uma "mini-ONU”, onde os Estados Unidos aceitariam dividir o poder com outros países com regimes repressivos, considerados "inimigos da democracia” e "da liberdade de expressão online”. Isso não é verdade.

Primeiro, porque as funções IANA tem muito pouco (ou quase nada a ver) com o conteúdo online. E, em segundo, porque os governos, na ICANN hoje, têm papel meramente consultivo. As prerrogativas de participação decisória que lhes foram dadas em virtude da transição restringem-se a aspectos de governança corporativa para a solução de controvérsias entre as políticas adotadas pelos diversos stakeholders e a forma com a qual são implementadas ou não tais políticas pela ação do funcionalismo da corporação. Isso, quando ocorrer, será feito por meio de uma espécie de assembleia política sem nenhum tipo de preponderância dos governos em relação aos demais atores.

Em teoria e na prática, há muita desconfiança e forte indesejabilidade de que o modelo intergovernamental de governança global seja adotado como modelo de referência para a governança da

8 A documentação sobre o processo de transição IANA encontra-se toda disponível em: https://www.icann.org/stewardship. Acesso em: 16/06/2017.

9 Um exemplo da ação de Cruz pode ser conferida no vídeo intitulado "Sen. Cruz Urges Colleagues to Stop Obama's Internet Giveaway”, disponível em: https://www.youtube.com/watch?v=OmqVW5v0wSw. Acesso em: 16/06/2017. 
Internet, em virtude do dinamismo do campo e do grande protagonismo de atores não governamentais na estruturação e no funcionamento das mais de 50 mil redes autônomas que dão forma à rede global.

Ao mesmo tempo, há atores que advogam que o unilateralismo histórico dos Estados Unidos em relação à raiz da Internet sempre foi objeto de contestação e que alimentou a ideia de que essa porção da governança da rede deveria ser abarcada por organizações intergovernamentais nos moldes da ONU ou da UIT. O governo brasileiro tem tido uma postura híbrida e equilibrada, que defende a necessidade de equilíbrio entre soluções intergovernamentais e soluções multissetoriais como instrumentos possíveis de serem implementados em esferas distintas da governança da rede. Quando Cruz advoga por unilateralismo com uma postura arrogante, fazendo barulho no ambiente doméstico dos EUA a ponto de ameaçar a estabilidade do processo de transição, ele pode estimular atores do peso de China e Rússia a perseguirem a ruptura institucional com o formato atual, desfavorecendo o diálogo conciliatório que foi patrocinado pelo Brasil, sobretudo até 2015.. Algo que poderia - em última análise - fragmentar a própria Internet como conhecemos hoje.

Independentemente dos detalhes e das disputas retóricas em torno do assunto no ambiente doméstico dos Estados Unidos, pode-se dizer que o assunto é de suma importância para a política internacional contemporânea. $\mathrm{O}$ assunto é absolutamente hermético e é natural que faça pouco sentido para o ensino e a pesquisa em Relações Internacionais no Brasil hoje. Por ser bastante específica, a questão da transição IANA tende a não preocupar os analistas e sua ausência no discurso de Temer talvez não tenha chamado atenção justamente por isso. Pode-se até eximir o atual Presidente de qualquer responsabilidade sobre a inserção do assunto em seu primeiro discurso na Assembleia Geral da ONU. É mais difícil eximir, porém, sua assessoria internacional.

Diante dos inúmeros esforços empreendidos no sentido de colocar o assunto na agenda internacional e de acompanhar e influenciar o processo que estava próximo de seu desfecho, pareceu um equívoco considerável que ele não tenha voltado a aparecer no discurso de Temer. Em uma era em que todas as tecnologias digitais convergem para a Internet e que o futuro da própria governança global passa, inevitavelmente, pela governança da rede, talvez tenhamos perdido a oportunidade estratégica de capitalizar em cima dos resultados (positivos ou negativos) da transição nos moldes em que foi desenhada no processo conduzido pela comunidade da ICANN. E, até mesmo, de revelar (se for o caso) eventuais preocupações com o possível abandono do consenso alcançado com o NETmundial em São Paulo em prol dos interesses nacionais estritos dos Estados Unidos, como a manutenção da sede da ICANN na Califórnia sem nenhum tipo de imunidade de jurisdição ter sido prevista. .

Obviamente, a tarefa do analista é ingrata, uma vez que talvez haja razões substanciais que se contrapõem às ideias acima e que jamais virão a público por fazerem parte dos cálculos políticos da assessoria internacional da presidência em um contexto que envolve múltiplos tabuleiros de jogo. Ainda assim, a exemplos de discursos anteriores dos supremos mandatários brasileiros na ONU, o enfrentamento da conjuntura internacional circundante, onde o futuro da governança da Internet ganha cada vez mais em 
centralidade, sobretudo em virtude da interseção crescente entre o uso da rede e diversas ameaças distintas à segurança internacional na atualidade, parece ter deixado a desejar.

\section{REFERÊNCIAS}

BRASIL. Discurso da Presidenta da República, Dilma Rousseff, na abertura do Debate Geral da $68^{\mathrm{a}}$ Assembleia Geral das Nações Unidas - Nova Iorque/EUA, 2013. Disponível em: http://www2.planalto.gov.br/acompanhe-o-planalto/discursos/discursos-da-presidenta/discursoda-presidenta-da-republica-dilma-rousseff-na-abertura-do-debate-geral-da-68a-assembleia-geraldas-nacoes-unidas-nova-iorque-eua. Acesso em: 16/06/2017.

BRASIL. Discurso da Presidenta da República, Dilma Rousseff, na abertura do Debate Geral da 69a Assembleia Geral das Nações Unidas - Nova Iorque/EUA, 2014. Disponível em: http://www2.planalto.gov.br/acompanhe-o-planalto/discursos/discursos-da-presidenta/discursoda-presidenta-da-republica-dilma-rousseff-na-abertura-do-debate-de-alto-nivel-da-69aassembleia-geral-das-nacoes-unidas-onu. Acesso em: 16/06/2017.

BRASIL. Discurso da Presidenta da República, Dilma Rousseff, na Abertura da $70^{\text {a }}$ do Debate Geral da Assembleia Geral das Nações Unidas - Nova Iorque/EUA, 2015. Disponível em: http://www2.planalto.gov.br/acompanhe-o-planalto/discursos/discursos-da-presidenta/discursoda-presidenta-da-republica-dilma-roussef-durante-abertura-da-70a-assembleia-geral-das-nacoesunidas. Acesso em: 16/06/2017.

BRASIL. Discurso do Presidente da República, Michel Temer, na abertura do Debate Geral da $71^{\text {a }}$ Assembleia Geral das Nações Unidas - Nova York/EUA, 2016. Disponível em: http://www2.planalto.gov.br/acompanhe-planalto/discursos/discursos-do-presidente-darepublica/discurso-do-senhor-presidente-da-republica-michel-temer-durante-abertura-do-debategeral-da-71a-assembleia-geral-das-nacoes-unidas-nova-york-eua. Acesso em: 16/06/2017.

CANABARRO, Diego. R. ; BORNE, Thiago. The Brazilian Reactions to the Snowden Affairs: Implications for the Study of International Relations in an Interconnected World. Conjuntura Austral. Porto Alegre, v. $6,2015.250-74, \quad$ p. 2015 em: www.seer.ufrgs.br/index.php/ConjunturaAustral/article/download/54617/34317. Acesso em: $16 / 06 / 2017$.

CANABARRO, Diego. R. O longo 2014 da governança da Internet - um balanço do 9o IGF. Politics, Rio de Janeiro, v. 19, p. 21-30, 2014. Disponível em: https://politics.org.br/edicoes/o-longo-2014-dagovernan\%C3\%A7a-da-internet-um-balan\%C3\%A7o-do-9\%C2\%BA-igf. Acesso em: 16/06/2017.

CASARÕES, Guilherme. Análise: A necessária legitimidade internacional. O Estado de São Paulo, São Paulo, 20/09/2016. Disponível em: https://politica.estadao.com.br/noticias/geral,analise-a-necessarialegitimidade-internacional,10000077276. Acesso em: 16/06/2017.

CASARÕES, Guilherme. Nada de novo no front: o discurso da presidente Dilma na ONU. Análise de Conjuntura do Núcleo de Estudos e Análises Internacionais - IPPRI/UNESP, 02/10/2015. Disponível em: http://neai-unesp.org/nada-de-novo-no-front-o-discurso-da-presidente-dilma-na-onu/.

EUA. NTIA Announces Intent to Transition Key Internet Domain Name Functions. Sítio eletrônico do Departamento de Comércio dos Estados Unidos, 14/03/2014. Disponível em: https://www.ntia.doc.gov/press-release/2014/ntia-announces-intent-transition-key-internetdomain-name-functions.

GONZALES, Alexandre A. Quem governa a governança a governança da internet? Uma análise do papel da internet sobre os rumos do sistema-mundo. Dissertação de Mestrado em Ciência Política, UFRGS, 2016. Disponível em: < http://hdl.handle.net/10183/140410 > Acesso em: 16/06/2017. 
LUCERO, Everton. Governança da Internet: aspectos da formação de um regime global e oportunidades para ação diplomática. Brasília: FUNAG, 2011.

MCCARTHY, Kieren. TRUMP: ICANN'T EVEN! America won't hand over internet control to Russia on my watch. The Register, 21/09/2016, San Francisco, EUA. Disponível em: https://www.theregister.co.uk/2016/09/21/trump_wading_into_iana_transition/. Acesso em: 16/06/2017.

STRICKLING, Larry. Reviewing the IANA Transition Proposal. Blog do Departamento de Comércio dos Estados Unidos, 11/03/2016. Disponível em: https://www.ntia.doc.gov/blog/2016/reviewing-ianatransition-proposal. Acesso em: 16/06/2017. 


\title{
RESUMO
}

Depois da reação a Snowden em 2013 e 2014, nenhuma palavra foi proferida sobre o assunto por Dilma Rousseff na Assembleia Geral da ONU em 2015. Em 2016, o atual presidente repetiu a lacuna. Parcialmente, pelas mesmas razões que explicam 2015. Entretanto, se a conjuntura abona a lacuna de 2015, o mesmo não vale para 2016. Este texto de análise de conjuntura procura apontar as razões de tal lacuna e refletir a respeito de suas consequências possíveis

Palavras-chave: Nações Unidas; Caso Snowden; Governança da Internet;

\begin{abstract}
After the reaction to the Snowden revelations in 2013 and 2014, the Internet was not mentioned by Dilma Rousseff at the opening ceremony of the UN General Assembly in 2015. In 2016, her successor was silent again. Such a silence is partially explained by the same set of reasons. Even though the circumstances in 2015 might absolve the gap, they do not condone it in 2016. This paper evaluates the gap and project its potential consequences.
\end{abstract}

Key-words: United Nations; Snowden Affairs; Internet governance. 